M+A Revista Electrónica de Medioambiente

ISSN-e: 18861-3329

http://dx.doi.org/10.5209/MARE.56881

\title{
Ecoética en el Perú. Participación ciudadana en el cuidado y protección del medioambiente
}

\author{
Joseph G. Rengifo Vásquez-Caicedo ${ }^{1}$ \\ Recibido: 1 de junio del 2017 / Enviado a evaluar: 2 de junio del 2017 / Aceptado: 24 de julio del 2017
}

Resumen. La ecoética, también denominada ética ambiental, es una disciplina que busca generar en la vida cotidiana del ser humano la aplicación de principios morales, valores, normas de conducta y decisiones, las cuales conlleven a establecer una relación armoniosa con el medio ambiente, inspirada en la búsqueda de la justicia social para todos sin la necesidad de discriminar por ideología, raza, sexo, casta, religión o nación. Para ello, la investigación plasmada en este trabajo tiene en consideración, la importancia de la ecoética como una parte integral del ser humano, donde a cada decisión que este tome, deberá considerar el impacto hacia el medio ambiente que podría generar sus determinaciones. De esta manera, se podrá transmitir a todos los seres humanos como ciudadanos responsables, el mensaje de que no importa si se toma una decisión por más pequeña que esta sea y no tenga el efecto o impacto que uno espera, basta solamente con el hecho de tomar conciencia en cada decisión que se tome, para generar una conducta adecuada y de concientización al momento de tomar una decisión más importante.

Palabras clave: Conciencia; ética; principios; impacto; protección.

\section{[en] Ecoethics in the Perú. Citizen participation in the care and protection of the environment}

\begin{abstract}
Ecoethics", also known as environmental ethics, is a discipline that seeks to incorporate moral principles, values, conduct norms, and decisions into the daily lives of individuals. These elements should bring forth a harmonious relationship with the environment. This relationship will be inspired in the search of social justice for all, and it will not discriminate between ideology, race, sex, religion, or nationality. To achieve this, the research hereby presented will consider the relevance of ecoethics as an integral part of the human being in that for every decision that he makes, he will have to consider any possible effects on the environment. This way the message will be delivered to every human being, as a responsible citizen, that it doesn't matter how insignificant a failed outcome - it is enough to generate an adequate behavior and the environmental conscience in the process of critical decision-making.

Keywords: Environmental conscience; ethics; principles; participation; protection.
\end{abstract}

1 E-mail: rengifojoseph@hotmail.com 


\title{
[fr] Ecoethics au Pérou. La participation des citoyens à la prise en charge et protection de l'environnement
}

\begin{abstract}
Résumé. Ecoethics, également appelé l'éthique environnementale est une discipline qui cherche à générer dans la vie humaine quotidienne l'application des principes moraux, les valeurs, les normes de comportement et les décisions qui vous obligent à établir une relation harmonieuse avec l'environnement, inspiré la poursuite de la justice sociale pour tous, sans la nécessité de discrimination par l'idéologie, la race, le sexe, la caste, la religion ou de la nation. Pour cela, la recherche incarnée dans le présent document prend en compte l'importance de ecoethics comme partie intégrante de l'être humain, où chaque décision qui est prise, doit tenir compte de l'impact sur l'environnement qui pourrait générer ses déterminations. De cette façon, il peut être transmis à tous les êtres humains en tant que citoyens responsables, le message que peu importe si la décision est plus petite à prendre et ne pas avoir l'effet ou un impact que vous attendez, nous avons besoin que le fait sensibilisation dans toutes les décisions prises pour générer adéquate et de sensibilisation lors de la prise d'un comportement de décision majeure.

Mots-clés: Sensibilisation; l'éthique; principes; impact; protection.
\end{abstract}

Cómo citar. Rengifo Vasquez-Caicedo, J.G. (2017): Ecoética en el Perú. Participación ciudadana en el cuidado y protección del medioambiente. M+A Revista Electrónica de Medioambiente, 18(1), 63-78.

Sumario. 1. Introducción. 2. El ambiente y la ética ambiental o ecoética. 3. Ecoética y participación ciudadana en España y Perú. 3.1. Ecoética y participación ciudadana en España. 3.1.1. Ecoética en España legislada con participación ciudadana. 3.1.2. Convenio de Aarhus de 1998. 3.1.3. Vías de participación. 3.1.4. Instrumentos de colecta de información. 3.1.4.1. Perfil Ambiental 2012. 3.1.4.2. Perfil Ambiental 2013. 3.1.4.3. Perfil Ambiental 2014. 3.1.4.4. Perfil Ambiental 2015. 3.2. Ecoética y participación ciudadana en Perú. 3.2.1. Instrumentos de colecta de información. 4. Análisis de desarrollo de la ecoética y la aplicabilidad de mecanismos de participación ciudadana ambiental en Perú y España. 4.1. Ecoética y Mecanismos en España. 4.2. Ecoética y Mecanismos en Perú. 5. Conclusiones. 6. Bibliografía.

\section{Introducción}

En los últimos años, se ha podido observar la preocupación a nivel mundial por los problemas medioambientales que afectan directamente a la vida humana y a sus generaciones futuras, especialmente las intervenciones públicas (Estados o Naciones) para intentar proteger (prevenir, mitigar y corregir) al medio ambiente de los daños que han sido ocasionados por la conducta de la sociedad en general.

Por mucho tiempo hemos tenido el pensamiento errado de que el medio ambiente ha estado a nuestro servicio como ser humano, por lo que siempre ha primado los intereses económicos y la mejor calidad de vida, todos ellos vinculados a los avances tecnológicos, industriales y científicos, sin importarnos el impacto ambiental que estaría ocasionando el desarrollo de estas actividades. Esta falta de ética ambiental también denominada ecoética, poco a poco se ha ido transformando para dar lugar a políticas públicas y acciones destinadas a conservar el medio ambiente, en la cual los seres humanos desarrollamos nuestras actividades diarias y cotidianas, sin el cual sería imposible nuestro desarrollo y sobre todo nuestra existencia.

En tal sentido, resulta importante analizar la importancia de la participación ciudadana en el cuidado y protección del medio ambiente, el fomento la ética 
ambiental y el desarrollo del conjunto de valores que permitirán que el hombre pueda vivir en armonía con la naturaleza, siendo necesario realizar un pequeño análisis de la problemática ambiental a nivel mundial, cuyo enfoque especialmente será orientado en los casos de España y Perú, con la finalidad de determinar cuáles son sus principales problemas ambientales y qué medidas se han tomado para mitigar los mismos; asimismo, se realizará un análisis comparativo de las acciones de participación ciudadana que se han adoptado en ambos países en los temas relacionados al cuidado del medio ambiente, a fin de extraer y proyectar nuevas ideas que en el Perú se podrían implementar para fomentar e implementar la ecoética como medio de concientización a la población para la protección del medio ambiente.

También es preciso señalar, que tan importante es conocer la definición de ética ambiental o también denominada ecoética y su utilización a nivel mundial a través de la aplicación de principios ecoéticos, teniendo en consideración que a partir de la Cumbre de la Tierra que fue celebrada en Río de Janeiro en 1992, se pone en manifiesto la necesidad de promover una participación real de la sociedad con la finalidad de lograr un desarrollo sostenible.

Finalmente, debemos reflexionar y concientizarnos que las plantas, el suelo, los animales, el agua y demás elementos que integran el medio ambiente, son necesarios para el desarrollo de la vida humana, por lo que debe resultar más que un derecho de los seres humanos de vivir en un ambiente sano y equilibrado en el cual realicemos nuestras actividades diarias, un deber inexcusable para todos el de conservar estos componentes ambientales y participar activamente en su cuidado. La responsabilidad en el cuidado y protección del medio ambiente y sus recursos naturales es una tarea de todas las personas que habitan este mundo.

\section{El ambiente y la ética ambiental o ecoetica}

A partir de la explotación de las actividades industriales del siglo $\mathrm{XX}$, ha crecido considerablemente la contaminación ambiental, por lo que ha generado una relación eterna (hombre - naturaleza). No en tanto, debe de considerarse que la naturaleza es parte de nosotros y no deberíamos usarla como un recurso para beneficio propio, sino para un bien común, que satisfaga a ambas partes, y como tal se debe de cuidar.

Según Sigmund Freud, cuando escribió "El malestar de la cultura", identificó tres fuentes del sufrimiento humano; el poder de la naturaleza, la caducidad de nuestro cuerpo, y nuestra insuficiencia para regular nuestras relaciones sociales. Las dos primeras son inevitables, pero la tercera no: ya que no se entiende porqué la sociedad no procura satisfacción o bienestar, lo cual genera una hostilidad hacia lo cultural y lo ambiental.

Atendiendo a lo que nos quiere decir Freud, y llevado a un análisis comparativo entre Perú y España, se ve un gran abismo de diferencias, siendo estas la "Cultura Educación y Ética Ambiental" de cada país, para poder entender cada país empezaremos por España, los últimos cinco años de la década de ochenta, algunos éticos españoles de la época no encontraban relación entre esta disciplina y los 
asuntos filosóficos, pero fines de los años noventa se erradica el pensamiento de superación de la condición humana como hombre sobre la naturaleza y se empieza a construir una filosofía con perspectiva medioambiental ${ }^{2}$. Aquí se genera la idea de relación entre el problema medioambiental y la ciencia, la técnica y la ética, estableciéndose la propuesta de rehabilitar a la naturaleza como norma y valor de la acción humana, donde se fomenta la conciencia del ser humano, que no solo es afrontar en colectividad las consecuencias sino también dar soluciones a los problemas ecologistas que se presentan día a día; siendo una técnica de justicia ecológica.

Asimismo, es importante señalar que la participación en la política medioambiental en España como forma de participación ciudadana atiende a dos modalidades o tipos de actuación: En primer lugar tenemos la participación de tipo orgánica, a través del cual los ciudadanos pueden incorporarse a los órganos administrativos de carácter consultivo a través de sus asociaciones representativas como por ejemplo Consejos de Asesores de Medio Ambiente, Consejos Consultivos de Proyectos, Juntas Rectoras y demás, aunque su incidencia en la toma de decisiones sea escasa debido al carácter consultivo y no decisorio que tienen estos órganos; $\mathrm{y}$, en segundo lugar tenemos la participación de tipo funcional, la cual establece la participación ciudadana fuera del aparato administrativo y que está orientada a ayudar y colaborar en la toma de decisiones, la cual se extiende a tres ámbitos de aplicación y actuación pública: a) participación y consulta en decisiones relacionadas con actividades o instalaciones con efectos sobre el medio ambiente como licencias municipales, EIA y demás; b) participación y consulta en la elaboración, aprobación y modificación de planes y programas con efectos significativos sobre el medio ambiente $\mathrm{y}, \mathrm{c}$ ) participación y consulta en la elaboración de disposiciones de carácter general de rango reglamentario ${ }^{3}$. En tal sentido, la participación en temas medioambientales en España, ha establecido acuerdo de análisis respecto al rol que tienen los ciudadanos en los conflictos socio ambientales, pues es ahí donde surgen las políticas ambientales, y su participación se sitúa por la defensa y protección del medio ambiente, así como la búsqueda de integración e intereses de los humanos.

España está muy organizada y estructurada en temas de participación ciudadana, ya que realiza un papel importante de concientización sobre medio ambiente, buscando mecanismos que puedan influir en la agenda pública y política, no sólo educando sino consiguiendo compromisos políticos. La normativa en España en relación a la ética ambiental y participación es muy estricta, clara y concisa, incentiva a los ciudadanos que participen del cuidado del medio ambiente activamente, algunos de instrumentos normativos que sirven de base para la generación de la conciencia ambiental son:

\footnotetext{
Velayos Castelo, C. (2014). La ecoética en España. La Albolafia: Revista de Humanidades y Cultura, p.129-151.

3 Martínez Iglesias, M.; Lerna Montero, I.; García, E. (2008). Políticas de medio ambiente y participación ciudadana. CIRIEC-España, Revista de Economía Pública, Social y Cooperativa, n61, p.179-201.
} 
- Convenio de Aarhus firmado en 1998 y con entrada en vigencia el 30 de octubre de 2001, establecido por la Comisión Económica para Europa de Naciones Unidas sobre acceso a la información, la participación del público en la toma de decisiones y el acceso a la justicia en materia de medio ambiente, partiendo del siguiente postulado: para que los ciudadanos puedan disfrutar del derecho a un medio ambiente saludable y cumplir el deber de respetarlo y protegerlo, deben tener acceso a la información medioambiental relevante, deben estar legitimados para participar en los procesos de toma de decisiones de carácter ambiental y deben tener acceso a la justicia cuando tales derechos les sean negados.

- Ley 27/2006, por la que se regula los derechos de acceso a la información, de partición pública y de acceso a la justicia en materia de medio ambiente, la misma que a su vez incorpora como una medida de ratificar el Convenio de Aarhus, las Directivas Comunitarias 2003/4/CE y 2003/35/CE para que puedan ser aplicadas al ordenamiento interno de España, las mismas que son relativas al derecho de acceso a la información y participación ciudadana en determinados planes y programas relacionados con el medio ambiente, la idea respecto de la promulgación de la referida Ley, es recogida expresamente del principio 10 sobre la participación de todos los ciudadanos en gestionar asuntos ambientales establecidos en la Declaración de Rio sobre el Medio Ambiente y el Desarrollo.

- Constitución española de 1978, la misma que en su artículo 45 configura el medio ambiente como un bien jurídico de cuyo disfrute son titulares todos los ciudadanos y cuya conservación es una obligación que comparten los poderes públicos y la sociedad en su conjunto. Todos tienen el derecho a exigir a los poderes públicos que adopten las medidas necesarias para garantizar la adecuada protección del medio ambiente, para disfrutar del derecho a vivir en un medio ambiente sano. Correlativamente, impone a todos, la obligación de preservar y respetar ese mismo medio ambiente.

También podemos señalar que las resoluciones y/o ordenanzas de las administraciones locales (comunidades autónomas y municipios) permiten el desarrollo de una adecuada participación ciudadana en el cuidado y protección del medio ambiente, las cuales abordan mucho el tema del reciclaje, consumo responsable, aprovechamiento de los residuos sólidos, concientización en el uso de vehículos motorizados y demás acciones favorables con el cuidado del medio ambiente, siendo que las decisiones administrativas en materia ambiental que se tomen sin tener en consideración o vulnerando el derecho de participación pública podrán ser recurridas.

En Perú, la palabra ecoética es desconocida por la ciudadanía, que por lo ocurrido y vivido en la época del terrorismo se convirtió en una sociedad individualista, pues todo colectivo que tenga que ver con un socialismo para mejorar o incentivar el progreso es tomado a mal por la misma sociedad, debido a que aún persiste el miedo por todo el daño causado, el peruano se preocupa por salir adelante así mismo, por obtener muchas cosas materiales a través del desarrollo de sus actividades y acciones 
cotidianas, mas no se ha preocupado por disminuir y/o mitigar los daños hacia el clima, biodiversidad y en general hacia todos los seres vivos que comprenden su territorio.

El cuidado del medio ambiente es un tema nuevo para el Perú puesto que en el 2005 se promulga la Ley General del Ambiente y recién en el año 2008 se crea el Ministerio del Ambiente y el 2009 se establece la Política Nacional del Ambiente.

Si bien el tema del cuidado y conservación del medio ambiente está regulado, la normativa no hace referencia al desarrollo de la ecoética, que con su definición y aplicación nos permitiría ir más a allá de instrumentos normativos que regulan nuestro comportamiento con el medio ambiente, ya generaría la aplicación de principios morales, valores y normas de conducta en pro del medio ambiente, pues la debida regulación de la aplicación de los principios morales hace que nosotros nos concienticemos y veamos cuales son nuestras deficiencias en nuestro comportamiento hacía con la naturaleza. Entonces se puede decir que el Perú en su legislación no ha podido identificar de manera explícita ¿qué es la ecoética?, su importancia, su ámbito de aplicación, ni su relación con la educación ambiental y la conciencia ecológica que permita mantener informada y educada a la población con valores a favor del medio ambiente, la misma que a su vez permitiría que existe una mayor incidencia en la participación ciudadana en aras de buscar la protección, mejora y cuidado del medio ambiente, donde se pueda tomar conciencia de que los problemas ambientales nos afectan a todos para el presente y para las generaciones futuras ${ }^{4}$.

Con respecto a la participación ciudadana, la sociedad no tiene conocimiento del gran poder de incidencia que tendrían en la toma de decisiones respecto a proyectos o propuestas en temas relacionados con el medio ambiente que se dan en el Perú, y a su vez estarían en la agenda política como un punto referente participativo, que permita implementar mecanismos, proyectos y soluciones en relación al cambio climático y al cuidado del ecosistema, la biodiversidad y la naturaleza.

La ineficacia de la participación ciudadana es tan notoria, porque no se trabaja conjuntamente con el Estado, y a su vez la poca participación que existe, se ve corrompida por los intereses individualistas de quienes la promueven, lo cual hace notar la falta de cultura y educación ambiental, donde los perjudicados por la violación a la naturaleza acontecidas actualmente, serán nuestras propias generaciones futuras.

El Perú no tiene un instrumento normativo que señale directa o indirectamente la aplicación de la ecoética como el punto de partida para el cambio de comportamiento de la sociedad peruana en beneficio del medio ambiente, pero si regula aspectos del medio ambiente, los mismos que son:

4 Pacheco Vargas, M. E. K. (2004). Conciencia Ecológica: Garantía de un Medio Ambiente Sano (tesis de maestría). Pontificia Universidad Católica del Perú, Lima, Perú. 
- La Constitución Política del Perú de 1993, la misma que establece en su artículo 2, que toda persona tiene derecho - ... al disfrute del tiempo libre y al descanso, así como a gozar de un ambiente equilibrado y adecuado al desarrollo de su vida , en tal sentido la presente carta magna señala que el ciudadano peruano está en el derecho de poder exigir al Estado, la no vulneración del medio ambiente donde desarrolla su vida cotidiana.

- La Ley General del Ambiente del 2005, en su Capítulo 4, en lo que respecta a la partición ciudadana, señala que todas las entidades del Estado con competencia ambiental tienen la obligación de brindar información pública sobre el ambiente, sus componentes y sus implicancia a la salud a quien lo solicite; asimismo, señala el derecho de todo ciudadano de interponer denuncias ambientales, ya sea por infracción a la normativa ambiental o por actividades económicas que generen algún tipo de contaminación que este vulnerando su derecho fundamental establecido en la Constitución.

- Decreto Supremo del año 2009, que aprueba el Reglamento sobre Transparencia, Acceso a la Información Pública Ambiental y Participación y Consulta Ciudadana en Asuntos Ambientales, la cual establece la reglamentación del procedimiento que debe seguir cuando el ciudadano solicita información en temas ambientales a las entidades que cuentan con competencia ambiental, así como la promoción que debería existir para ejercitar la participación ciudadana.

- Plan Nacional de Educación Ambiental del 2017-2022, promulgado el 2016, la cual, en virtud de contribuir al desarrollo sostenible del Perú, señala como estrategia aplicar el enfoque ambiental en las instituciones educativas, a fin de desarrollar procesos de educación ambiental que se encuentren orientados a promover la participación ciudadana activa e informada a nivel local, regional y nacional.

\section{Ecoética y participación ciudadana en España y Perú}

\subsection{Ecoética y participación ciudadana en España}

Carmen Velayos Castelo, nos enseña que la ética ecológica no solo es una aplicación más que pueda estar normada o coaccionada a aplicarla, esto va más allá, pues la ética no está determinada por la ecología o el ambiente, pero si evoluciona natural y socialmente. La ecoética nos enseña a ver al hombre no solo como un sujeto más, si no como sujeto natural que forma parte de él, tenemos que tener en cuenta que a la naturaleza se le debe - respeto, - cuidado y - responsabilidad ${ }^{5}$. En este sentido, coincido con David MacCabe en un perfeccionismo pluralista: - los seres humanos pueden hacer juicios sensatos sobre el tipo de principios mediante los que deberían ser gobernados y sobre esas formas de vida que les aportan bienes importantes. Dada 
la naturaleza diversa de esos bienes, los perfeccionistas pluralistas querrán dar especial protección al ejercicio de la decisión individual, pero también querrán fomentar esfuerzos colectivos para proteger e impulsar esas formas de vida que hacen posibles dichos bienes ${ }^{6}$.

\subsubsection{Ecoética en España legislada con participación ciudadana}

La participación ciudadana se encuentra vinculada con derechos y libertades fundamentales que definen lo que se suele entender como una sociedad democrática, las opiniones de su ordenamiento jurídico señalan la diferencia entre participación política y participación ciudadana en España como en otros países no se tenía organizaciones y asociaciones que velen por el cuidado del medio ambiente y los ciudadanos no sabían cómo actuar frente a problemáticas medioambientales, habiendo normas a favor del medio ambiente; es por ello, que con la implementación de una cultura y educación ambiental y el incremento de diferentes conflictos ambientales, permitieron que la participación de la ciudadanía se acerque a la política, en busca de estructuras colectivas y diversas que les permitieran ser participe y actores en las decisiones políticas sobre temas ambientales, entre ellas están las asociaciones de vecinos, entidades encargadas, ONGs, y demás.

\subsubsection{Convenio de Aarhus de 1998}

Tiene como objetivo principal proteger el derecho de cada generación presente y futura, a vivir en un medio ambiente que permita garantizar su salud y su bienestar, y a garantizar los derechos de acceso a la información sobre el medio ambiente, la participación del público en la toma de decisiones y el acceso a la justicia en materia medioambiental.

Para conseguir estos objetivos, el Convenio de Aarhus parte de las siguientes consideraciones y reconocimientos:

a) Toda persona tiene el derecho a vivir en un medio ambiente que le permita garantizar su salud y su bienestar, y el deber, tanto individualmente como en asociación con otros, de proteger y mejorar el medio ambiente en interés de las generaciones presentes y futuras.

b) Para poder estar en condiciones de hacer valer este derecho y cumplir con ese deber, los ciudadanos deben tener acceso a la información, estar facultados para

6 Mccabe, D. (2009). - Knowing about the good: a problem with antiperfectionism , en Ethics, The University of Chicago, p.110, p.311-338, p.331. 
participar en la toma de decisiones y tener acceso a la justicia en asuntos ambientales.

c) Un mejor acceso a la información y una mayor participación del público en la toma de decisiones permiten tomar mejores decisiones y aplicarlas más eficazmente, contribuyen a sensibilizar al público respecto de los problemas ambientales y le dan la posibilidad de expresar sus preocupaciones ${ }^{7}$.

\subsubsection{Vías de participación}

a) Información: en este nivel se recoge todo tipo de información tanto ascendente (de ciudadanos a autoridades) como descendente (de autoridades a ciudadanos).

b) Consulta: en este nivel se consulta a los ciudadanos su opinión con el objetivo de mejorar las decisiones tomando en cuenta las ideas, críticas y propuestas de éstos. Esta consulta puede hacerse a través de diferentes instrumentos: encuestas de opinión, encuestas de satisfacción, estudios de impacto, reuniones públicas, referendo, conferencias de consenso, consultas directas a través de Internet, etc.

c) Concertación: en este nivel se considera a los ciudadanos como expertos e intervienen permanentemente en grupos o asociaciones en los procedimientos administrativos o en la formulación de las políticas públicas locales.

d) Adopción de decisiones: se adoptan decisiones conjuntamente con las autoridades o en lugar de éstas. Se podría denominar la auténtica participación ya que implica compartir el poder con los políticos locales convirtiéndose en una codecisión entre los habitantes y sus representantes. Entre estos mecanismos podemos destacar: el referéndum decisorio, la creación de comisiones de usuarios de los servicios públicos, la cogestión y gestión directa o el presupuesto participativo.

\subsubsection{Instrumentos de colecta de información}

\subsubsection{Perfil Ambiental 2012}

En este perfil ambiental se encuentra, planes, programas y medidas ambientales, que constituyen la política medio ambiental, puestas en marcha tanto por la administración como por las políticas locales, de esta forma se establecen los mensajes claves de los sectores y áreas más relevantes. Con el principal fin y objetivo de cuidar y salvaguardar los elementos que conforman el medio ambiente como el agua, aire y los espacios naturales, a través de la implementación de políticas de

7 Vice Consejería de Medio Ambiente, Convenio de Aarhus (1998): información, participación y acceso a la justicia en temas ambientales. 
desarrollo sostenible, donde la participación ciudadana organizada y respeto del medio ambiente, siendo principal en cada política gubernamental destinada a la reducción de la contaminación.

\subsubsection{Perfil Ambiental 2013}

En este perfil ambiental hace mención a la evolución y crecimiento con los años anteriores respecto al estado del medio ambiente y la importancia que ha tenido la participación ciudadana y su conciencia adquirida en relación al cuidado y protección del ambiente donde realizan sus labores cotidianas, también siguieron con la reducción de las emisiones de gases, ya que desde el 2007 se ha producido una reducción importante de las emisiones totales por habitante y por unidad de PIB siendo una de las bajas de Europa, lo que ha generado que el Estado incentive a la población en conocer los efectos del cambio climático y cuáles son las acciones que como ciudadanos les corresponde realizar a fin de ayudar a la protección del medio ambiente (reducción de las emisiones de huella de carbono).

\subsubsection{Perfil ambiental 2014}

El Perfil Ambiental de España cumplió con este los 11 años, pues a lo largo de estos años se generó conciencia sobre el cuidado, protección y respecto hacia las áreas naturales y las riquezas que brindan; cabe mencionar que la conservación de espacios y especies se ha visto reforzada por el desarrollo de estrategias de conservación de flora y fauna, integrando todos los componentes ecológicos del territorio, fomentando su protección y mejorando la integración de la población con el medio.

\subsubsection{Perfil ambiental 2015}

En este perfil ambiental, incluyeron dos temas con suma importancia que les beneficiaba como país, tanto individualmente como colectivamente; el primero fue denominado "Hacia una economía verde" y la segunda "Uso eficiente de recursos". Ambas materias son disciplinas básicas de sostenibilidad ambiental y económica en el marco actual de impulso de la economía circular, que aspira a integrar el medio ambiente en los sectores económicos y productivos, señalando como punto importante la educación y cultura ambiental que la sociedad ha adquirido en lo que respecta a la generación de un aprovechamiento sostenible de los recursos que brinda la naturaleza ${ }^{8}$.

8 Perfil Ambiental de España 2015 Informe basado en indicadores, Ministerio de Agricultura y Pesca, Alimentación y Medio Ambiente Madrid 2016, p. 11. 


\subsection{Ecoética y participación ciudadana en Perú}

El D.S. $N^{\circ}$ 002-2009-MINAM, menciona sobre el acceso a la información ambiental, que toda entidad pública tiene la obligación de facilitar información a quien se lo solicite, sin distinción alguna, estableciendo mecanismos, facilitando el acceso, establecer criterios o medidas, difundir información gratuita, eliminar las exigencias, rendir cuentas acerca de las solicitudes a la Autoridad Nacional del Ambiente, y entregar la información que se esté solicitando teniendo en cuenta que no es tan promovida, y sabiendo que es un derecho fundamental la participación pues no se ejecuta. Ahora, esta participación es un deber que tiene todo ciudadano mas no es aplicada o actuada porque las autoridades (local, regional, nacional), no promueven una capacitación, ni tampoco realizan una orientación ni difusión de cómo es que se puede acceder a esta participación.

Una ley importante es la Política Nacional del Ambiente, que tiene como objetivo específico la activa participación ciudadana de manera informada y consciente en la toma de decisiones para el desarrollo sostenible, con una participación justa y equitativa de los beneficios que esta derive. La participación ciudadana es considerada como un derecho constitucional, está contemplado en el Artículo $2^{\circ}$, Numeral 17 de la Constitución Política del Perú, en el que se establece que toda persona tiene derecho a -Participar en forma individual o asociada en la vida política, económica, social y cultural de la Nación . Es así que, específicamente el derecho a la participación ciudadana ambiental otorga a toda persona el derecho a participar de manera responsable en los procesos de toma de decisiones sobre asuntos referidos a la gestión ambiental que pudieran tener alguna incidencia sobre sus intereses ${ }^{10}$.

La participación ciudadana, es la participación, por parte de la sociedad civil, en los asuntos públicos del país pues es un derecho fundamental, reconocido por los tratados y pactos internacionales suscritos por el Estado, los cuales establecen que toda persona tiene derecho a participar en los asuntos públicos de su país ${ }^{11}$.

9 D.S. N ${ }^{\text {0 }}$ 002-2009-MINAM, Art. 20 (Decreto Supremo que aprueba el Reglamento sobre Transparencia, Acceso a la Información Pública Ambiental y Participación y Consulta Ciudadana en Asuntos Ambientales).

10 Fátima, C. (2015). El derecho de acceso a la participación ciudadana ambiental en actividades mineras. Sociedad Peruana de Derecho Ambiental, p. 11.

11 Constitución Política del Perú de 1993 establece en su Artículo 31‥- Los ciudadanos tienen derecho a participar en los asuntos públicos mediante referéndum; iniciativa legislativa; remoción o revocación de autoridades y demanda de rendición de cuentas. Tienen también el derecho de ser elegidos y de elegir libremente a sus representantes, de acuerdo con las condiciones y procedimientos determinados por ley orgánica. Es derecho y deber de los vecinos participar en el gobierno municipal de su jurisdicción. La ley norma y promueve los mecanismos directos e indirectos de su participación. Tienen derecho al voto los ciudadanos en goce de su capacidad civil. Para el ejercicio de este derecho se requiere estar inscrito en el registro correspondiente. El voto es personal, igual, libre, secreto y obligatorio hasta los setenta años. Es facultativo después de esa edad. La ley 
La Ley General del Ambiente, en su primer capítulo en el Art. II, habla sobre el derecho a la información, la cual señala que toda persona tiene el derecho a acceder adecuada y oportunamente a la información pública sobre las políticas, normas, medidas, obras y actividades que pudieran afectar, directa o indirectamente, el ambiente, sin necesidad de invocar justificación o interés que motive tal requerimiento ${ }^{12}$. El acceso a la información está regulado, solo es de uso para personas jurídicas, con esto no se menciona que solo este dirigida para ellos; solamente que es más usado y aplicado por ellos, ya que actualmente de cada 50 personas 2 buscan información de cómo se puede mejorar o como pueden aportar en pro de la naturaleza ${ }^{13}$, entonces volvemos a repetir que a la sociedad peruana en general, tiene infinidad de instrumentos normativos que llegarían a cambiar su comportamiento con el medio ambiente, pero lamentablemente la falta ética, cultura y educación ambiental no permite mejorar su actuar.

\subsubsection{Instrumentos de colecta de información}

El Sistema Nacional de Información Ambiental - SINIA, como una de sus funciones es de brindar información a la población, empresas y entidades públicas en relación a los asuntos ambientales que ocurren a nivel nacional y que sirve para acceder a la información pública ambiental.

En ese sentido, al momento de solicitar dicha información, se puede ver que la realidad del Perú es otra, puesto que no se tiene una educación y cultura ambiental inculcada, aparte del desinterés de las autoridades por fomentar un cuidado del medio ambiente, del lugar donde vivimos, teniendo conocimiento que no solo es para nuestro presente, sino, que a medida que se cuide el medio ambiente nuestra generación sabrá y se dará cuenta que valió la pena el esfuerzo de toda una población.

Sin embargo, el Perú ha hecho un esfuerzo importante en cuanto al fortalecimiento de la fiscalización ambiental por conducto del OEFA, cuya finalidad es asegurar el cumplimiento de la legislación ambiental. ${ }^{14}$ Sin embargo, las normas legales ambientales que se refieren al ordenamiento territorial son muchas, en diferentes

establece los mecanismos para garantizar la neutralidad estatal durante los procesos electorales y de participación ciudadana. Es nulo y punible todo acto que prohíba o limite al ciudadano el ejercicio de sus derechos.

12 Ley General del Ambiente de Perú, Derechos y Principios, Artículo II.- Del derecho de acceso a la información, Toda persona tiene el derecho a acceder adecuada y oportunamente a la información pública sobre las políticas, normas, medidas, obras y actividades que pudieran afectar, directa o indirectamente, el ambiente, sin necesidad de invocar justificación o interés que motive tal requerimiento. Toda persona está obligada a proporcionar adecuada y oportunamente a las autoridades la información que éstas requieran para una efectiva gestión ambiental, conforme a Ley.

13 INEI, Encuesta de acceso a la información de las entidades públicas,2015.

14 Ministerio del Ambiente (2016), Evaluación del Desempeño Ambiental Perú 2016, pág., 32 
ámbitos y con superposiciones, lo que dificulta entender su alcance y fuerza jurídica ${ }^{15}$.

\section{Análisis del desarrollo de la ecoética y la aplicabilidad de mecanismos de participación ciudadana ambiental en Perú y España}

\subsection{Ecoética y Mecanismos en España}

España como país desarrollado ha sido capaz de inculcar en su población la concientización y respeto a favor del medio ambiente, donde prevalece mucho el factor filosófico y ético respecto del comportamiento del ser humano en mejora de la naturaleza, donde se tiene la convicción que el ser humano es parte de la naturaleza por ende debe cuidarla y velar por su sostenibilidad.

Con el desarrollo e instauración de una participación ciudadana activa, se ha observado resultados óptimos en beneficio del medio ambiente, donde la relación jurídica del Estado con las organizaciones, asociaciones y grupos ecologistas ha sido viable, debido a que estas últimas han cumplido una función informativa, donde dan a conocer a la población en general la existencia de instrumentos legales que han sido promulgadas en beneficio de la conservación y respeto del medio ambiente y que deben ser aplicadas y respetadas; no en tanto, las autoridades públicas o administraciones, tienen pleno conocimiento de la importancia y relevancia que tiene el cuidado del medio ambiente, lo que demuestra por ejemplo que las Comunidades Autónomas indistintamente, establecen mecanismos de protección y conservación del medio ambiente a través de la instauración de políticas ambientales autonómicas que generan una sensibilización en la población y reeducan favorablemente el comportamiento de los mismos en favor de la naturaleza

\subsection{Ecoética y Mecanismos en Perú}

El Perú como un país en desarrollo, utiliza y aprovecha las riquezas naturales que le brinda su ecosistema para mejorar su economía; sin embargo, este crecimiento se ve desvalorizado debido a que la instauración de políticas ambientales son escasas, lo que genera que no exista un adecuado desarrollo sostenible con respeto hacia el medio ambiente y su vez exista una falta de educación ambiental en la ciudadanía, lo que conlleva a indicar que el concepto de ecoética es por mucho desconocido en el Perú; también se observa que los mecanismos de participación ciudadana establecidos para proteger el medio ambiente son pocos a comparación con España, donde si bien está regulado la participación ciudadana y existen instrumentos legales que protegen

\footnotetext{
15 Ministerio del Ambiente (2016), Evaluación del Desempeño Ambiental Perú 2016, pág., 33
} 
al medio ambiente, estas no son promovidas por el Estado para que puedan ser aplicadas y ejercidas por la población en general.

La mayoría de autoridades públicas y administraciones del Perú no tienen conocimiento de la importancia de cuidar del medio ambiente, esto debido a que el Estado les ha otorgado facultades para que estas puedan establecer mecanismos de mitigación y protección ambiental, pero resulta ineficiente debido al desinterés que muestran estas administraciones de instaurar mecanismos que conlleven a dicho fin, y a su vez generen una participación activa de la población en pro de la conservación, mitigación y protección ambiental.

\section{Conclusiones}

Al existir un desconocimiento en el Perú sobre el concepto de ecoética como un estudio que establece aspectos filosóficos y éticos del ser humano en el área de las ciencias ambientales, que conllevan a la implementación de principios y valores éticos que guiarán, normalizarán y regularizarán el compartimiento del ser humano en favor de la naturaleza, donde a su vez deberá prevalecer la idea tan importante como es que la naturaleza, sus recursos y riquezas no le pertenecen al hombre, y es más bien el hombre el que desarrolla sus actividades dentro de un todo que es la naturaleza, ha generado que la población realice sus actividades cotidianas sin respeto alguno al medio ambiente, sin pensar en las repercusiones que esto podría traer para generaciones futuras, mostrándose indiferente hacia el cambio climático y que a su vez por la falta de promoción del Estado respecto al cuidado y protección del ambiente, el derecho participativo de la ciudanía como colectivo o de manera individual se muestre mermado en pro del medio ambiente.

En relación a la cultura ambiental que debería existir en la población peruana y comparándola con el actuar de la población española, se ha podido observar ingratamente, es que existen ciudadanos que conocen de los mecanismos de participación ciudadana en beneficio del medio ambiente; sin embargo, prima mucho el egoísmo y la indiferencia, en primer lugar la indiferencia hacia con la naturaleza porque el actuar de protección a través de una participación es escasa, ya que no lo ejercen como deber y derecho, mostrándose indiferentes en el cuidado, respeto, protección y conservación del medio ambiente donde desarrollan sus actividades cotidianas, y en segundo lugar existe el egoísmo de difundir estos mecanismos de participación a otros ciudadano que lo desconocen, ya que la educación y cultura que se tiene en Perú, no permite razonar sobre la importancia que tiene el cuidar del medio ambiente, lo que conlleva a no tomarle importancia y por ende generar el desinterés del ciudadano de tener un rol activo en la toma de decisiones a favor del medio ambiente, concluyendo que no existe una adecuada organización y trabajo en conjunto entre estado y sociedad, lo que conlleva a que no se pueda generar un efecto multiplicador que permita informar sobre los diferentes mecanismos de cuidado al medio ambiente. 
Educar para lograr una estabilidad ambiental implica dar soluciones, llegar acuerdos, generar conciencia y actuar en pro del medio ambiente, tanto en el ámbito individual como colectivo, teniendo en cuenta que la participación ciudadana toma parte de la solución de conflictos, aportando ideas nuevas, diferentes puntos de vistas, etc. Sin embargo, Perú como estado y con la división de responsabilidades con los otros niveles de gobierno, no ejecuta políticas ambientales solidas que permitan el involucramiento de la sociedad civil en la toma de decisiones ambientales. La división de estas responsabilidades políticas ambientales es un punto débil del Estado peruano, pues se considera que el tema relacionado al cuidado y protección del medio ambiente es solo responsabilidad del gobierno central; por tanto, la existencia de actividades contaminantes sumado a la desinformación de la población en general y al desconocimiento de las funciones ambientales de las distintas autoridades en los otros niveles de gobierno, ha generado que los hechos y acciones contaminantes sean consentidos en un país, que de manera calmosa y progresiva va tomando conciencia sobre la importancia que tiene proteger el medio ambiente y combatir el cambio climático.

Finalmente, concluyo que el cambio de cultura y educación ambiental de la población peruana es responsabilidad de dos entes el Estado y la Sociedad, primeramente el Estado deberá asentar el concepto de ecoética como punto de partida para generar una conciencia ambiental, y esto se dará a través de la instauración de políticas educativas ambientales dirigidas a la sociedad, que conlleva a que esta pueda comportarse en respeto con el medio ambiente en base a principios y valores éticos y morales, donde se priorice el respeto a la naturaleza como el todo. Esta instauración del concepto de ecoética deberá ser secundada por la adecuada capacitación a los distintos niveles de gobierno a fin de que conozcan sus funciones ambientales y así promuevan la conservación, protección, cuidado y responsabilidad ambiental y sobre todo incentiven la participación ciudadana individual o colectiva a nivel nacional, y sobre todo inculcar la importancia que tiene la ciudadanía en la toma de decisiones que involucren temas ambientales, donde se vea vulnerado su derecho constitucional de vivir en un ambiente sano y equilibrado que les permita realizar sus actividades cotidianas en respeto con el medio ambiente.

\section{Bibliografía}

Constitución Política del Perú de 1993, Artículo $31^{\circ}$.- De la participación ciudadana en los asuntos públicos, Perú.

D.S. N ${ }^{\circ}$ 002-2009-MINAM (2009), Artículo 20 (Decreto Supremo que aprueba el Reglamento sobre Transparencia, Acceso a la Información Pública Ambiental y Participación y Consulta Ciudadana en Asuntos Ambientales), Lima, Perú.

Fátima, C. (2015). El derecho de acceso a la participación ciudadana ambiental en actividades mineras. pag.11.Sociedad Peruana de Derecho Ambiental.lima.peru.

INEI, (2015), Encuesta de acceso a la información de las entidades públicas, Perú. 
Ley General del Ambiente de Perú (2005), Derechos y Principios, Artículo II.- Del derecho de acceso a la información, Lima.

Martínez Iglesias, M.; Lerna Montero, I.; García, E. (2008). Políticas de medio ambiente y participación ciudadana, Revista de Economía Pública, Social y Cooperativa, n 61 , p.179201. CIRIEC-España.

Mccabe, D. (2009). - Knowing about the good: a problem with antiperfectionism , en Ethics, the university of Chicago, p.110, p.311-338, p. 331, Chicago.

Ministerio del Ambiente (2016), Evaluación del Desempeño Ambiental Perú 2016, p. 32 .Perú

Ministerio del Ambiente (2016), Evaluación del Desempeño Ambiental Perú 2016, p. 33.Perú.

Pacheco Vargas, M. E. K. (2004). Conciencia Ecológica: Garantía de un Medio Ambiente Sano (tesis de maestría). Pontificia Universidad Católica del Perú, Lima, Perú.

Perfil Ambiental de España 2015 Informe basado en indicadores, Ministerio de Agricultura y Pesca, Alimentación y Medio Ambiente, 2016, p.11.Madrid.

Velayos Castelo, C. (2013). La ecoética en España, Síntesis, p.137, Madrid.

Velayos Castelo, C. (2014). La ecoética en España. La Albolafia: Revista de Humanidades y Cultura, p.129-151, España.

Vice Consejería de Medio Ambiente, Convenio de Aarhus de 1998: información, participación y acceso a la justicia en temas ambientales, Madrid, España. 